\title{
Techniques of Teaching English by Information-Communication Technologies (The North-Eastern Federal University)
}

Irina Lvovna Savvina

Department of Foreign Languages of Technical and Natural Sciences, North-Eastern Federal University, Yakutsk, Russian Federation

Anna Gavrilievna Krivoshapkina

Department of Foreign Languages of Technical and Natural Sciences, North-Eastern Federal University, Yakutsk, Russian Federation

Sardana Ivanovna Prokopieva

Department of Foreign Languages of Technical and Natural Sciences, North-Eastern Federal University, Yakutsk, Russian Federation

Evgeniya Efimovna Yadrikhinskaya

Department of Foreign Languages of Technical and Natural Sciences, North-Eastern Federal University, Yakutsk, Russian Federation

Doi:10.5901/mjss.2015.v6n3s3p255

\section{Abstract}

The article contains research of the education system and techniques of teaching English to students of non-linguistic faculties by communication technologies in all aspects of cognition, education and science at the North-Eastern federal university in Republic Sakha (Yakutia) Russia. The authors analyze language teaching to students of non-linguistic specialties according to the Federal State Educational standards. The purpose of this paper is to reflect upon the value and role of learning activity with a proposal of possible measures that could be taken to improve foreign-languages teaching in the university by means of information-communication technologies. The article contains research of the educational system capable to provide effective communication of specialists in global space as a necessary condition of education quality of the modern students.

Keywords: teaching foreign languages; non-linguistic faculties, information-communication technologies in education; pedagogical issues; teaching/learning strategies.

\section{Introduction}

\subsection{Introduce the Problem}

The progress of international cooperation in all spheres of life has increased the demand of highly-qualified specialists with a good knowledge of foreign languages. Foreign languages have a great potential for the development of the personality. Learning foreign languages gives both knowledge and influences on the development of the mobile personality, ready for self-education, life-long learning, ability to understand the cultures of Russia and other countries. A foreign language is a source of intellectual, cultural and professional development of the personality and a factor of social-economic, scientific-technical and cultural progress of the society.

\subsection{Importance of the Problem}

The importance of our research is the world society integration cooperating for the development of education, science and new technologies that demands the development of informative learning activity of students studying foreign languages for their self-education, self-control, self-development breaking all communication problems.

The creating of differently new educational system capable to provide effective communication of specialists in modern global space is a necessary condition of education quality of the modern students.

The development of modern technologies, the Internet, has opened huge variety of information resources. At the same time, with the development of technologies the learning process that causes the continuous self-education is being accelerated. It causes the transition from the concept "education for the rest of life" to the concept "education through all the life" (life learning), that makes education of the personality capable to autonomous self-education. 
Any expert in his professional sphere needs up-to-date information which mostly is presented in foreign language media. Modern means of communication give the huge opportunities of informative search and communication. Professional activity of the expert of any profile demands ability to use databases, to search information, to process various documents, to edit texts. The enterprises need intelligent and well-educated, competent employees. Success of realization of professional ambitions of any expert depends on his business qualities: abilities to see a problem, to solve the problem, to analyze information, to make decisions and to be responsible for it, practical abilities, discipline, communicative skills. In the conditions of the extending international cooperation, the demand of the experts who know foreign languages is increasing.

Nowadays the foreign language has to make such impact on the personality, the result of which will be transformed to the spontaneous emotional and mature intellectual and informative organism capable to solve any cultural communicative situations by means of creative or unique instruments of search, processing and practical application of information.

Methods of education, widespread in Russia, are focused not on the process, but on the result. Teaching a foreign language has to be aimed not only on the result, but also on the process.

\subsection{Relevant Scholarship}

The analysis of research results of the leading scientists and field-specific literature shows significant theoretical development of the teaching foreign languages. Special attention should be paid to scientific researches of the Russian and foreign scientists who considered the theoretical bases of the learning activity and information-communication technologies while foreign languages studying.

There are various pedagogical definitions of "learning activity". The analysis of scientists' works (L.A. Aristova, R.A. Nazamova, N.A. Polovnikova, T.I. Shamova, G.I. Shukina), the given concept can be specified as follows: learning activity is a steady condition of the person with a set of components developing strong personal qualities of the specialist to support and improve personal motivation of individual learning through active foreign language learning (Savvina I.L. The development of learning activity of students while studying a foreign language. Yakutsk, 2003).

T.I. Shamova and others suggest that activity has a very important role which it actually carries out. It should be considered as an individual didactic category. It's a motivation, influencing on its efficiency. Therefore it should be considered not only as a condition, but also as the means of achievement of education tasks. Thus the relation both to it and to the subject, and knowledge are closely connected. The negative perception of the subject reduces activity, weakens tendency to the purpose. On the contrary, special attention to the learning process can lead to such situation when the final aim is disappeared and illusion of its absence is appeared.

The development of learning activity of students while studying foreign languages is realized through structural stages-components of knowledge: motivation-purposeful, information-programmed, communicative, correctionsupervising, reflexing:

- The organization of teaching and educational process is focused, first of all, on satisfaction of requirements of an individual, instead of the abstract person, including (E.V.Bondarevskaya ideas) axiological (introduction in the world of personal-significant system of valuable orientations), cognitive (supply with scientific knowledge of the human being, culture, history as a basis of inner development), action-creative (development of activity and abilities necessary for self-realization in personal, scientific, other spheres) and personal (self-education, development of reflective ability, self-control, self-improvement) components.

- Students' requirements for intellectual, moral, informative development are a dominating role in learning motivation defining teacher's work. We support J.K.Babansky, A.K.Markova, G.I.Shukina's pedagogical ideas who consider, that positive motivation is promoted by the general atmosphere in the group, informative content updating, teaching methods, demanding active interesting emotional material; cognitive methods, the analysis of life situations, group and personal experience in their future professional work.

- Studying process is students' development in the sphere of knowledge, experience, work - i.e. subjectivity development. The cognitive content is the construction of categorial world, creative imagination, search of unknown and paradoxical, decentralization and purpose, search of methods of realization, the control over passive realization, etc. The results pay attention to the revealing of the learning importance, self-expression, etc. Such organisation provides students with self-valuable intentions, such as reflexion, decentralization, categorization, independence, no samples, etc.

- Cognitive (informative) activity of students is formed by maintenance of the «over individual education» (V.A.Petrovsky). Its mechanism is student's tendency to the self-valuable and self-sated forms of activity that 
is expressed in operation, activity, business, actions. Psychological phenomenon "aspiration" has both valuable and tool aspects, that finally expressed as I "want" and I "can" actions. Such actions make this process for students as a pleasure when I "can" turns into I "want".

- The educational environment for personification of a student in the group community in the learning activity is created. In this community the person, as a rule, feels difficult inconsistent processes. Sources of these processes are contradictions between two "I": "I" in the eyes of the individual and hypothetical own "I" in another opinion (immersive "I"), as discrepancy "I" in his own eyes and immersive "I" of the individual. For overcoming of these contradictions our model joins identifications of the individual with real or imagined people of that community in which the student aspires to be personalized himself. The conditions for active-adaptive actions of all participants of educational interaction are created.

- The educational environment is characterized, on the one hand, as «social organization», on another hand, as «entity community». «Social organization» is always particularly individual within cooperative activity and has a target determination. "Entity community» is quite definitely cooperative activity. It has the same valuable bases (Savvina I.L. The development of learning activity of students while studying a foreign language. Yakutsk, 2003).

The model «entity community» supposes teacher-student's interaction as "co-entity". Developing student's learning activity, the teacher shows the tendency to knowledge, creativity, experience. It is possible to reach that when the traditional social-focused position of the teacher is replaced by his anthrop-focused position in pedagogical process.

Thus, the criterion of the pedagogical process developing the personality and his learning (informative) activity, is self-development ("plan-realisation-reflexion"). In the course of realisation of the given triad the student builds or reconstructs his image, realises activity of self-knowledge, self-determination, in particular, through the self-directed learning (informative) activity.

The special role in modernization of education belongs to the modern information and communication technologies. The scientists think that the increase of value of the information in our society is characterized:

- $\quad$ as «informative explosion» (T.V. Andrianova, J.V.Rekzema, V.I.Sidorov, A.N.Efimov, etc.),

- $\quad$ as «information crisis» (V.A. Vinogradov, R.S.Gilyarovsky, A.I.Mikhailov, A.I.Cherny, etc.),

- as «information revolution» (N.N.Moiseyev, A.I.Rakitov, etc.) (Bosikova K. Increase of educational activity of students by means of information and communication technologies (on the example of studying foreign languages), Yakutsk, 2009).

The scientists think that the primary goal of communication technologies is informative activity of students through access to modern informative-educational resources (to web technologies, multimedia, to the various databases, educational sites, etc.).

\subsection{State Hypotheses and Their Correspondence to Research Design}

The epoch of globalization, process of the world economic and cultural informative integration has come. There are changes in the world educational space in the conditions of global information tendencies. These tendencies today are the priority directions of the educational policy of Russia. In «Concepts of modernization of Russian education» the methods of modernization and optimization, active use of information-communication technologies in the higher schools have been presented. «The national doctrine of Russian education» has defined the basic directions of education with the use of information-communication technologies: creating the effective controlling system of information-methodical supply of education, the organization of students' learning activity while teaching - learning the foreign language.

Our research has the following contradictions:

- between needs of society for the experts with the professional communicative foreign-language competence and limited opportunities of practice of foreign language at non-linguistic faculties;

- between needs for highly qualified professionals, capable to accumulate information, and insufficient study of the problem in the pedagogical theory;

- between needs for establishment of the international business cooperation and poor communicative foreignlanguage skills of experts.

The research is devoted to solving of the following conceptual problems. The development of learning activity of students while studying foreign languages will be effective if:

learning activity is a specific integration of stable personal abilities determine student's skills to get and apply his knowledge for some cognitive tasks;

the levels of learning (informative) activity while foreign languages studying depends on the teaching-learning 
technologies;

effective didactics develop learning activity of students;

the model of learning activity development aims at special environment including professional content and interaction.

As learning activity is the important stimulus creating «the internal developing environment», it considerably changes educational activity, influencing on its character, functioning and result. Being stable, it becomes the motivation power of the student's progress. It defines learning activity, the initiative. It is an indicator of the general competence of the person.

The technology used in teaching-learning process is caused by many factors. Such social-psychological circumstances are taken into account: the structure and requirements of the person depending on his I.Q. and other individual abilities, national-ethnic features, etc.

\section{Method}

One of the major characteristics of the qualified specialist nowadays is foreign languages skills in the epoch of globalization, scientific and technical progress. Thus we tried to organize the educational process in such a way to develop student's leaning activity. We tries to interest them, create modern situations. Therefore the methods were not only traditional, but mostly with the use of a complex of information-communication technologies. Let's speak about some of our methods.

Our research testifies that students' curiosity does not change into cognitive (informative) activity. There are 3 traditional stages of the development of learning activity. But we follow 4 stages system of the development of learning abilities while learning a foreign language to control the development of the student's level of learning activity.

1. The first level of learning activity is fixation of studying material in student's memory. This is a reproduction level - the ability to know and remember the previous studied material.

2. The second level - algorithmic. It's student's ability to self reproduction and its use in various similar situations. It doesn't need new information and skills.

3. The third level - partially-search. It's student's ability to get information from his memory, to transform, combine and apply it in partially new situations.

4. The fourth level - research level. Its student's ability to active search of new cognitive tasks, to get knowledge himself, active reflex, self-education. Thus it transforms into professional motivation. level.

The aim is to help students to reach the highest level of learning activity from stage to stage without missing any

These levels testify what stage the student is at the moment and what he needs: stimulation, control, sample, support, etc. Every next level means the change and success of the student. Our research experimental data at the beginning of the semester were the following:

- $\quad 9 \%$ of students show high level.

- Sufficient level (partially search) - $11 \%$.

- $\quad$ Average level (algorithmic) - $34 \%$.

- $\quad$ Low level (reproduction) - $45 \%$.

As Web 2.0 and the plethora of associated technologies and tools (e.g. wikis, blogs, podcasting, FaceBook, YouTube, Flickr) has created new opportunities and challenges for education, we decided to apply them for teaching foreign languages.

We, teachers of foreign languages department of technical and natural specialties of the Institute of foreign philology of North-eastern federal university named after M.K. Ammosov (Siberia) participated in the international project «Web tools 2.0» with the university Purdue (the USA). The leaders were Tim Newby and Larissa Olesova. Other useful courses were initiated by Teresa Almeida De'ca, Portugal TESOL specialist, Yakut TESOL events and others. We have received a great opportunity to know the up-to-date information-communication technologies and practice with the students of various non-linguistic faculties.

The projects' tasks were - to create the online site allowing teachers to create, exchange ideas with colleagues, students, to know new actual information, professionally develop according to new tendencies.

The term Web 2.0 was coined in late 2004. According to Stephen Abram, Web 2.0 goes beyond the 'Web 1.0 paradigm of web sites, email, search engines and surfing'. He suggests that: 'Web 2.0 is more about the human aspects of interactivity. It's about conversations, interpersonal networking, personalization, and individualism' (Abram, Stephen (2006, January) Web 2.0, Library 2.0 and Librarian 2.0: preparing for the 2.0 world). 
We analyzed different web 2.0 program as Blogging, Chat Tools, Charts \& Graphs, File Sharing \& Mashups, Microblogging, Notebooks \& Annotation Tools, Online Office Suite, Online Presentation, Personal Web Portals, Photo Editing/Sharing, Screen Recorders, Search Engines, Social Bookmarking, Social Network, Survey \& Polling Tools, Task \& Group Management, Video Chat, Video, Editing/Sharing, Website Creation, Wikis, Group Template Page and others (http://www.itap.purdue.edu/learning/cdm/supporting/FlippedModel/TechnologyConsiderations.html). following:

The first project meeting has taken place by means of video-conference between universities. We agreed on the

1. Acquaintance of participants of the project and the description of duties in a team from each university (researchers-searchers, planners of lessons, technical support, the designer of the unit, the editor, stitchers, presenters).

2. Distribution of tasks weekly.

3. Date definition on the first-subsequent information interchange. Coordination of all actions between teachers and students was carried out by means of e-mail and video-conferences on technology Skype.

Teamwork was the following:

1. week has been devoted to the search, analysis, exchange of the new information about the program among participants of group through e-mail or video-conference and additions on the special page of comments of university Purdue (Shpankov I. Stand aside, Photoshop! www.mirsovetov.ru/a/hi-tech/network/onlinephotoeditor.html).

2. week was devoted to the analysis and comparison of this program with other similar programs of 2.0 generation.

3. week was devoted to the planning of lessons for 3 levels: primary, secondary and higher education according to the American education standards. We have prepared plans of lessons for all levels in the field of medicine, economics, mathematics, history and geography.

4. week - preparation and practical help to the American students for the project presentation, final videoconference.

At the lessons we used some most popular tools with the lesson plans for different levels interesting to students:

\section{YouTube}

The purpose of YouTube is view and share videos. No one really knows how many videos are uploaded to YouTube currently. That is no surprise considering that for every minute that passes by, 48 hours of video are uploaded. That adds up to 8 years of video being uploaded every day. YouTube can have multiple purposes, whether it's to show a classroom an educational video, or to entertain your for a few hours, YouTube has any video to meet any need. For many, YouTube is the first, and only, internet site to search for videos of all kinds. Whether the video is about the political election, the daily news, a funny blooper or a missed TV episode, YouTube has it all. More recently, educators are beginning to value the internet sites that their students have been using in their leisure time. Educators now understand the power of the Internet and how using this new technology can be beneficial to their students (https://wiki.itap.purdue. edu/display/INSITE).

Hanover Research (2013) notes: "...educators implementing a classroom flip should select simple, accessible, and familiar technology."

Technology is always changing and teachers should redo about $50 \%$ of them per semester and $100 \%$ in a year. Instructors who teach a course with rapidly changing subject matter must build in time to redo videos and materials on a frequent basis. Dr. Newby notes, however, that when he lectured he would still have to revise his lectures constantly, so the pressure to revise was still there. He advises instructors to use material editing software that makes it easy to cut and insert changes to existing ones.

Dr. Newby, McGivney-Burelle \& Xue, Dr. Regena Scott (2013) have some advice for teachers at site: http://www. itap.purdue.edu/learning/cdm/supporting/FlippedModel/TechnologyConsiderations.html:

"Creating, editing, and posting videos are time-consuming endeavors as is the development of the in-class quizzes and problem sets. On average, for every class meeting, it took us about 1.5 hours to make one short video and an additional 45 minutes to prepare the quiz and in-class problem set. In contrast, preparing a traditional lecture typically takes us less time. However, once the initial technical and logistical problems were resolved, we were able to spend less time creating a video. Once a polished set of videos and course materials are created the preparation time will be significantly reduced..." 


\section{Skype}

The main purpose of Skype is to connect people. People from around the world can connect through many different ways. Skype is great for all teachers. A teacher could utilize Skype in instances of distance learning or cultural I language learning. For instance, a teacher could teach students geographically separated by lecturing through Skype on the computer while the students sit in their homes anywhere in the world. Calls concerning questions about the lecture would be free of charge between Skype users. Another example might include the Yakut teacher who has students interface with students from the English speaking country in order to explore and learn about culture and language, benefiting students of both parties. Since Skype is available in 28 different languages, students can use it to communicate with other students across the world to learn their language and culture.

\section{Wiki}

Wikia allows users to create and develop "communities" or wiki pages for virtually any topic. It can be used in many different languages, which allows people all over the world to utilize it. Wikia is free to use and it is free to create an account. Account members can edit the wiki page content. Wikipedia, a well-known wiki site, provides neutral or nonbased information to readers. Jimmy Wales, the founder of Wikipedia and co-founder of Wikia, feels that Wikia does not require the same neutrality as Wikipedia. The webpage can also be used to search for different articles. There is a search bar located on the site where users can simply type in the topic for which they are looking.

1. We'd like to pay more attention to one tool that is successfully used often:

Pixenate - free on-line graphic editor of images, the product of Irish company Sxoop Technologies Ltd., created in 2005. The head is William Higgins. The site address is http://www.sxoop.com.

Advantages: free, simple, convenient interface; there is no necessity for registration; amusing tools in the form of snow and oil paint; it is easy to receive images for its subsequent editing; integration with Flickr. Pixenate is used only for fast editing of one picture for once. It is enough to come on web page, to load and edit.

Disadvantages: insufficient control of many tools; no printing (A.Krupinin. Дюжина фооторедакторов для браузера; I.Shpankov. Stand aside, Photoshop; Он-лайн фоторедакторы).

Awards: the most innovative Irish website 2008-09 (www.awards.ie/webawards/2008/09/moviestar-web-awards).

The work with the editor has 3 stages:

1. Loading of the editor from the site www.pixenate.com (free)

2. Loading of the image, or from the site

3. Editing

The base set of pictograms (18) includes allocation of the image or its part, scale and size change (it is no more 1600 on 1200), turn on fixed and any corners, change of colour scale to a black-and-white format, light, brightness, contrast, alignment in relation to horizon (Spirit level), removal of "effect of red eyes» and "bleaching" function. The set of additional tools (8) includes amusing details: text addition, закругление corners, a snowflake, a clip-art, a heart, a framework, etc.

4. Saving in the format jpeg

Pixenate is integrated with the popular photoarchive Flickr (G.Lowensohn. 15 он-лайн фооторедакторов; http:// scyuen.wordpress.com/2007/12/28/photo-editing-free-online/).

As this program practically is not used in Russia (data on its application in educational process was not found), search of the given information has occupied a lot of time (www.mirsovetov.ru/a/hi-tech/network/online-photoeditor.html). We were not familiar with the given program earlier.

We practiced 'Pixenate' with the 2 year students of Medical Institute (Medical faculty). The students after learning the topic «Diseases of the respiratory system» transformed a picture of healthy lungs depending on different kinds of the disease with the use of program Pixenate. The lesson plan with the use of program Pixenate, was aimed on modeling of the life situation, practicing of the future expert professional, social and creative functions. 


\begin{tabular}{|c|c|}
\hline Prior Knowledge & Students have a general knowledge of medicine and diseases \\
\hline Objectives & $\begin{array}{l}\text { Students will : } \\
\text { - } \quad \text { Introduce students to the symptoms of the respiratory diseases (www.moodle.ysu.ru) } \\
\text { - } \quad \text { Allow students to learn about prophylactic methods against respiratory diseases } \\
\text { - } \quad \text { Show a presentation for Students to see what different diseases are actually like (should use diseases } \\
\text { - } \quad \text { with visual symptoms: hepatitis, lung cancer, alcoholism, smoking, others) } \\
\text { Each Student will individually create a picture of human organism affected by a respiratory disease by } \\
\text { using Pixenate program. }\end{array}$ \\
\hline $\begin{array}{l}\text { Teacher } \\
\text { Preparation }\end{array}$ & $\begin{array}{ll} & \text { Make all copies (symptoms, analyses, prophylactic methods) } \\
\text { - } & \text { Computers with Internet (Pixenate program installed) } \\
\text { - } & \text { Have all necessary information about respiratory diseases }\end{array}$ \\
\hline $\begin{array}{l}\text { ISTE/NETS } \\
\text { Standards }\end{array}$ & $\begin{array}{l}\text { 1. Facilitate and Inspire Student Learning and Creativity } \\
\text { Teachers use their knowledge of subject matter, teaching, and learning, and technology to facilitate experiences } \\
\text { that advance student learning, creativity, and innovation in both face-to-face and virtual environments. } \\
\text { Teachers: } \\
\text { - } \quad \text { promote, support, and model creative and innovative thinking and inventiveness } \\
\text { - } \quad \text { resources } \\
\text { - } \quad \text { promote student reflection using collaborative tools to reveal and clarify Students' conceptual } \\
\text { understanding and thinking, planning and creative processes } \\
\text { model collaborative knowledge construction by engaging in learning with students, colleagues, and } \\
\text { others in face-to-face and virtual environments }\end{array}$ \\
\hline Materials & $\begin{array}{ll}\text { - } & \text { Computers in computer lab with Internet access } \\
\text { - } & \text { Pixenate program installed } \\
\end{array}$ \\
\hline Anticipatory Set & $\begin{array}{l}\text { Anticipatory Set (10 Minutes) } \\
\text { Explain what are respiratory diseases, what were pandemic of the } 17^{\text {th }} \text { century - till present time, } \\
\text { causes of different diseases } \\
\text { - Ask the students what they know about such diseases as hepatitis, lung cancer, alcoholism, others }\end{array}$ \\
\hline Instructions & 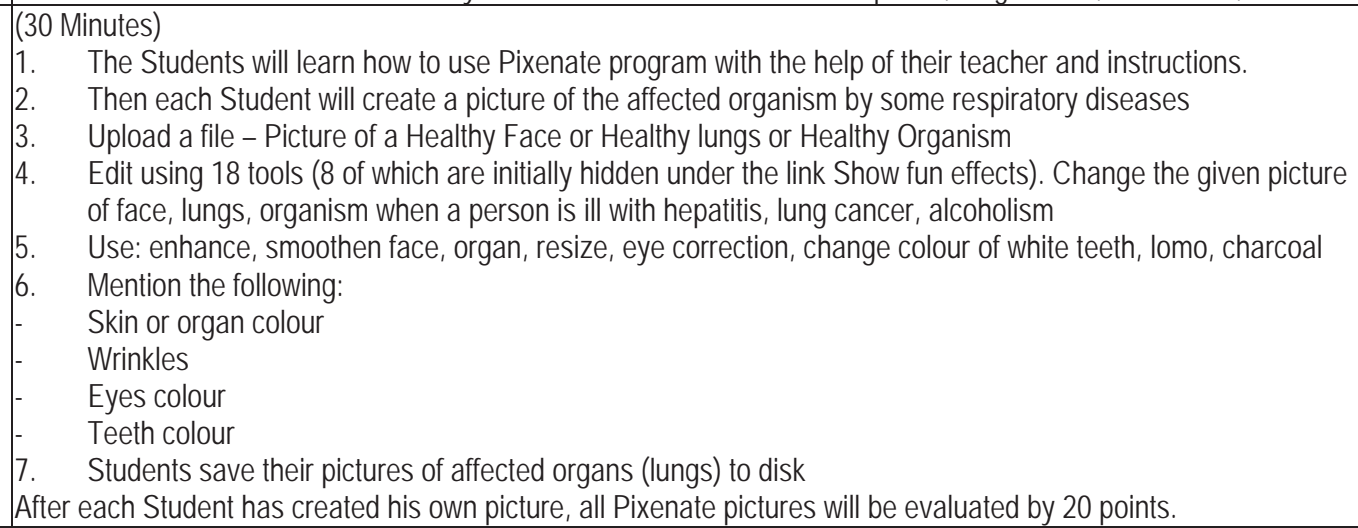 \\
\hline Closure & $\begin{array}{c}\text { Closure (5 Minutes) } \\
\text { Turn to face of a healthy man ;) and BE HEALTHY }\end{array}$ \\
\hline
\end{tabular}

This project certainly has enriched our information-communication technologies experience in educational process. As a result, you can see our cooperative web page on the site: http://www.wiki.itap.purdue.edu/display/INSITE

\section{Results}

Due to the use of information-communication technologies, the final research data revealed that there were essential changes of learning (informative) activity. Students have changed a low level to the higher. The number of students preferring productive learning, research interest, practical skills have increased. Students began to search new information more, thought about their self-education more. Their level of activity in the course of education has changed their professional orientation and results of practical skills, having increased the number of highly-qualified doctors speaking English. The results were the following: 
- $\quad 23 \%$ of students have high level

- Sufficient level (partially search) - $27 \%$.

- Average level (algorithmic) - $25 \%$.

- Low level (reproducing) - $25 \%$.

$-$

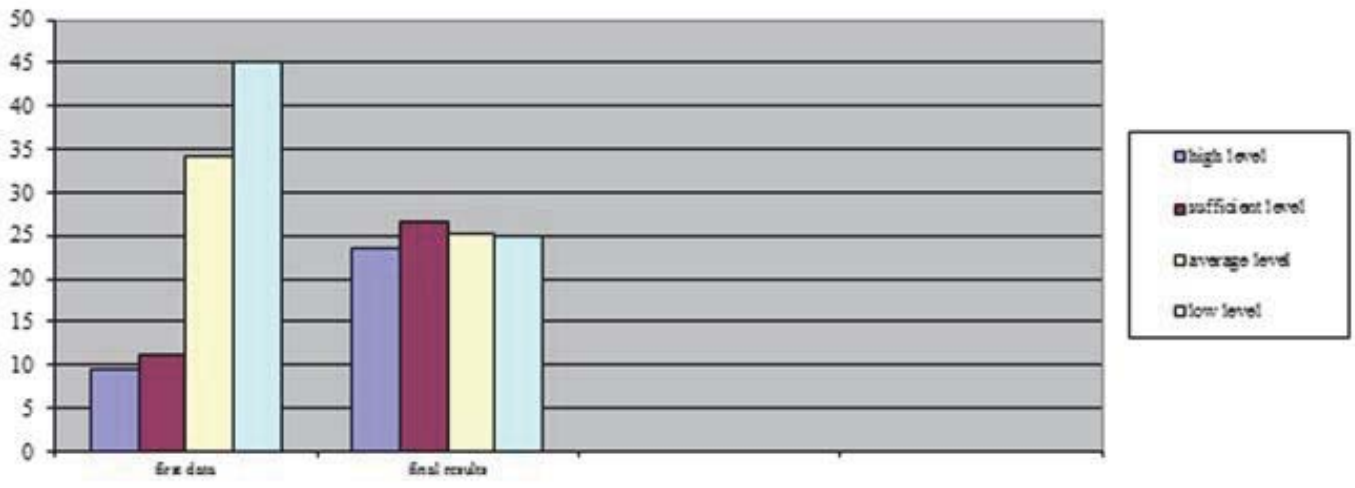

Figure 1. The diagram of learning activity of students

It was established that only $9 \%$ of students had a high level of learning activity at the beginning of experimental work. But the use of professional tasks at the positive orientation aimed at future professional activity has been noted; transition from pragmatical to valuable orientations. And by results of forming experiment stage the indicator grew to $23 \%$.

Sufficient level (partially searching) was changed from $11 \%$ to $27 \%$. Knowledge was sufficient for all kinds of professional work; sufficient intellectual and informative abilities for use in a familiar, standard situation.

The average level (algorithmic) was changed from $34 \%$ to $25 \%$. The cognitive interest to the study was shown more as motivation of wellbeing and prestige; organizational, intellectual, communicative, information abilities are expressed partially; sufficient formation of informative abilities for use in a familiar, standard situation.

The low level (reproduction) changed from $45 \%$ to $25 \%$. It's sufficient for work with educational, popular scientific literature with the use of the dictionary; the abilities connected with the cogitative analysis of conditions of the problem are poorly presented.

As a result, students have shown more independence, initiative. The position of the teacher has changed too. We (teacher) cause students self-control.

\section{Discussion}

Thus, the research showed that the educational foreign language process was based on the computer technologies (web 2.0 tools, various Internet text, sound and video data) as an additional material for individual work. It helped to develop students' skills of purposeful selection of the information for individual work.

We were guided by such ideas that information technologies are not important themselves in the educational process. It is important how much their use can help to achieve educational purposes; good results, increase students' learning activity. It's important to have good effective quality educational course with the means of information technologies

Questionnaires have shown that the use of information-communication technologies in educational process raised students' interest, educational, informative and learning activity while studying the foreign language.

In conclusion we'd like to note that the development of students' learning activity is provided by certain conditions: professional motivation while foreign language study; effective modern pedagogical methods focused on educational activity; use of the information-communication technologies promoting inclusion of students in creative, research work of future specialists.

The comparison of results of the first and last experiments have demonstrated the dynamics of significant increase of informative activity of students of experimental group from the reproduction level to the high level of practical development of all indicators while algorithmic level was prevailing for the end of training among students of control group. 
However we have much to do for practical recommendations aimed at the development of the identity of each student. It is necessary to make more for regularition of the development of personal potential of students and technology of learning process.

\section{Conclusion}

The research was devoted to solving of some conceptual problems as the development of learning activity of students while studying foreign languages. Having analyzed some theoretical works, we've presented 4 stages system of the development of learning abilities while learning a foreign language. We've proved that the development of learning activity will be effective when:

1. Learning activity is a specific integration of stable personal abilities that determine student's skills to get and apply his knowledge for some cognitive tasks;

2. The levels of learning (informative) activity while foreign languages studying depends on the teaching-learning technologies;

3. Effective didactics develop learning activity of students;

4. The model of learning activity development aims at special environment including professional content and interaction.

5. Information-communication technologies create great opportunities and challenges for education.

The learning activity creates «the internal developing environment» of the student considerably changing his educational activity, influencing on his skills, study and results. When it becomes stable, it becomes the motivation power of the student's progress. It is the indicator of the general competences of the highly qualified experts.

\section{References}

Abram, Stephen (2006, January) Web 2.0, Library 2.0 and Librarian 2.0: preparing for the 2.0 world. SirsiDynix OneSource. 2,1 Retrieved on January 23, 2008 from: http://www.imakenews.com/sirsi/e_article000505688.cfm?x=b11,0,w

Bosikova K. (2009) Increase of educational activity of students by means of information and communication technologies (on the example of studying foreign language). (Thesis ... candidate of pedagogical sciences). - Yakutsk, 2009.

http://scyuen.wordpress.com/2007/12/28/photo-editing-free-online/

http://www.itap.purdue.edu/learning/cdm/supporting/FlippedModel/TechnologyConsiderations.html

http://www.sxoop.com

https://wiki.itap.purdue.edu/display/INSITE

Krupinin A. Dozen photoeditors for the browser. Retrieved from http://www.rusdoc.ru/articles/djuzhina_fotoredaktoro_dlja_brausera/17

Lowensohn G. 15 online photo editors. Retrieved from www.news.chet.com

On-line photos editors. Retrieved from http://emax.ru/leisure/article/read570.html

Savvina I.L. (2003). The development of learning activity of students while studying the foreign language. (Dissertation ... candidate of pedagogical sciences). - Yakutsk, 2003.

Polyakov J.A., Gilinskaya T.S., Pomelova M.S. and others. The use of information-communication technologies: monograph. Krasnoyarsk, 2011. 
ISSN 2039-2117 (online) ISSN 2039-9340 (print)
Mediterranean Journal of Social Sciences MCSER Publishing, Rome-Italy
Vol 6 No $3 \mathrm{~S} 3$ May 2015 